\title{
Molecular Physiology of Insulin Function
}

\author{
Amin Ibrahim* \\ Medical officer, Ayodele medical center, Iju, Lagos State, Nigeria.
}

\author{
Received: September 19,2019; Accepted:November 27,2019; Published: December 3,2019 \\ *Corresponding author: Dr. Amin Ibrahim, medical officer, Ayodele medical center, Iju, Lagos State, Nigeria; Tel: +2348134517941; E-mail: ibrahimam- \\ in23@yahoo.com
}

\begin{abstract}
Insulin is a peptide hormone that is secreted by the pancreatic $\beta$-cells and it plays a pivotal role in a number of cellular metabolic processes. Structurally, it consists of two chains that are connected by disulphide bonds. It is secreted from the $\beta$-cells upon membrane depolarization and opening of potassium sensitive ATP channels. This process can be initiated by several stimuli especially glucose entry into the cell. Insulin signal transduction starts with binding of the receptor which belongs to the tyrosine kinase family and phosphorylation of Insulin Receptor Substrates. Consequently, two well defined pathways i.e. the phosphoinositide-3-kinase which is involved in carbohydrate, lipid and protein metabolism as well as the MAP-kinase pathway which mediates mitogenesis are established. Insulin enhances glycolysis and glycogenesis while inhibiting gluconeogenesis and glycogenolysis. It also promotes lipogenesis and inhibit lipolysis. These effects are possible because of its ability to activate and deactivate several enzymes and other substrates via phosphorylation. It is also involved in the induction of genes coding for important enzymes in these pathways. The effects of insulin extend to the regulation of vascular structure and function partly through its ability to stimulate nitric oxide production. The aim of this article is to summarize the molecular mechanisms behind the most important insulin functions.
\end{abstract}

\section{Introduction}

The isolation of insulin in 1922 by Fredrick Banting and Charles Best marked the beginning of a new era in the treatment of diabetes. Before then patients with diabetes were given weeks, months or a year to live after diagnosis but the work of these two men revolutionized diabetes treatment and significantly extended the lifespan of those treated with the new therapy. The decades that followed saw massive research towards the development of insulin from animal to human insulin and analogs. Today, insulin is central to the management of both type 1 and type 2 diabetes. 425 million people had diabetes in 2017 and $5-10 \%$ of these have T1DM requiring insulin for life. There is thus a need for the better understanding of insulin science with the intention of translating this knowledge into the development of biomarkers and therapeutic agents. The study of the actions of insulin at the molecular level is undoubtedly an essential requirement for the progressive realization of this research objective.

\section{Structure}

The insulin molecule is a peptide with 51 Amino Acid (AA) residues [1]. It consists of two chains, the $A$ and $B$ chains linked by two disulphide bonds. The A chain has $21 \mathrm{AA}$ residues while the $\mathrm{B}$ chain has 30 . A third disulphide bond connects the 7 th and $11^{\text {th }}$ residues of the A chain [1]. Insulin exists as monomer, dimer and hexamer [2]. At neutral $\mathrm{pH}$ it exists as a monomer in low concentration and as a dimer in higher concentration [3]. The monomer is the active form which binds to the receptor. In the presence of zinc ions, it aggregates to form hexamers [4]. The structural configuration of hexameric insulin has been a subject of extensive research. In 1969 Dorothy C. Hodgkin's and co-workers determined the two zinc ions stabilized Porcine hexameric insulin structure [5] using X-ray crystallography. This well recognized model is designated as $\mathrm{T}_{6}$ [4]. A second crystal form (4 Zn-insulin) observed in the presence of increased $\mathrm{NaCl}$ concentration [6] is labelled $\mathrm{T}_{3} \mathrm{R}_{3} \mathrm{f}$ while the third family is known as $R_{6}$ [7]. These three families represent the transitional phases of insulin hexamer. The understanding of this structural heterogeneity has greatly been exploited for therapeutic gains in production of several insulin analogs that suit different needs in the treatment of diabetes.

\section{Insulin Secretion}

Beta cells secretion of insulin is initiated in the presence of several stimuli, the most potent of which is glucose [8]. Several events occur in the $\beta$-cells which culminates in the exocytosis of insulin containing vesicles. The glucose transporter GLUT 2 carries glucose into the cell [9] and it is metabolized to glucose6-phosphate (G-6-P) by hexokinase/glucokinase. G-6-P enters the glycolytic pathway where it is further metabolized yielding ATP. This increases the ATP/ADP ratio within the cell leading to closure of ATP sensitive potassium $\left(\mathrm{K}_{\text {ATP }}\right)$ channels and depolarization of the $\beta$-cell membrane [10]. The $\mathrm{K}_{\text {ATP }}$ channel has two subunits, an inward rectifying/pore forming subunit, Kir6.x and the sulfonylurea receptor (SUR) [11]. Binding of substrates to any of these can trigger the inhibition of KATP channel [12]. Sulfonylureas and related drugs generally bind to the SUR1[13] while others e.g. antimalarials (e.g. mefloquine) and phentolamine bind to Kir6.2 [14,15]. The incretin hormones GLP 1 and GIP are capable of inhibiting these channels through a cAMP dependent 
mechanism and stimulate insulin release [16]. Membrane depolarization opens voltage dependent calcium channels (VDCC) with ensuing $\mathrm{Ca}^{2+}$ influx and increased intracellular concentration $[10,16,17]$. VDCCs (a.k.a. Voltage Gated Calcium Channels) are present in several cells particularly excitable cells [18]. They are so named because of their permeability to $\mathrm{Ca}^{2+}$ and they open in response to depolarized membrane potentials. Since $\mathrm{Ca} 2+$ concentration is higher extracellularly, the opening of these channels is mandatory for certain calcium dependent physiologic actions e.g. muscle contractions, neurone excitation or hormone release [18]. Although, several types of VDCCs (L-type, N-type, P/Q-type, R-type) have been identified, the L-type appears to be the most important in the process of $\beta$-cells insulin secretion [19]. The $\mathrm{Ca}^{2+}$ influx drives the momentum for insulin vesicle exocytosis. Insulin is stored in large vesicles which will have to fuse with the membrane in order to empty their content into the extracellular space. Besides the cellular process of insulin secretion described above, other pathways have equally been identified that could be independent or augment the glucose stimulated $/ \mathrm{K}_{\text {ATP }}$ channel pathway [16]. The incretin hormones GLP-1(Glucagon-like Peptide) and GIP (Glucose dependent Insulinotropic Peptide) are potent stimulators of insulin secretion above a critical glycaemic threshold. These hormones bind G-protein coupled receptor and activate adenylate cyclase $[20,21]$ leading to cAMP formation which in turn activates protein kinase A (PKA). PKA is capable of inhibiting $\mathrm{K}_{\text {ATP }}$ channels possibly through the phosphorylation of residues in the SUR 1 receptor and induce insulin secretion [22]. The enzyme phospholipase C catalyzes the hydrolysis of phosphatidyl inositol 4,5 biphosphate to inositol 1,4,5-triphosphate (IP3) and diacylglycerol (DAG) in the presence of $\mathrm{Ca}^{2+}$. DAG activates protein kinase $\mathrm{C}$ while IP3 mediates $\mathrm{Ca}^{2+}$ release from the endoplasmic reticulum. Again, this increased $\mathrm{Ca}^{2+}$ concentration drives insulin vesicle exocytosis [16].

Glucose stimulated insulin secretion is typically a biphasic phenomenon [8]. The initial phase occurs rapidly upon meal ingestion and last for some minutes while the later phase is much more prolonged. The insulin secreted in the first phase is from the readily releasable pool (RRP) and newly synthesized molecules mostly account for the second phase secretion. Defective first phase $[23,24]$ and altered second phase insulin secretion is characteristic of T2DM [24].

\section{Signal Transduction}

Insulin signal transduction is a complex process that involves phosphorylation of several proteins which in turn activate other molecules until the desired cellular action is produced. A detailed explanation of the process is clearly beyond the scope of this article hence only the important points will be highlighted. The insulin receptor is a tetrameric protein with $\alpha$ and $\beta$ subunits joined by disulphide bonds [25]. The $\alpha$ subunit is extracellularly located while the $\beta$ subunit is transmembrane and possess intrinsic tyrosine kinase activity $[25,26]$ which gives insulin a broad involvement in cellular processes. The $\alpha$ subunit contains the hormone binding site and hormone binding triggers a conformational change and activation of tyrosine kinase activity leading to autophosphorylation of the tyrosine residues in the subunit which in turn phosphorylates insulin receptor substrates [IRS)[27]. IRSs are docking proteins i.e. they possess a N-terminal binding region for pleckstrin homology $(\mathrm{PH})$ and phosphotyrosine-binding domain (РTB) [28] as well as multiple tyrosine phosphorylation sites for the binding of proteins with Src homology 2 (SH2) domain [29]. The IRS family consists of six members [1-6]. Only IRS $1 \& 2$ are known to mediate most actions in the insulin signal transduction pathway [30]. Receptor activation causes IRS 1 to be phosphorylated at potentially more than 20 sites [31] hence, the impetus to interact with several downstream effectors. The two major pathways resulting from this interaction are the phosphoinositide 3-kinase (PI-3K) which effects metabolic actions and mitogen activated protein kinase (MAP-kinase) which undertakes cell growth and differentiation.

\section{PI-3 kinase pathway}

PI3K has a regulatory (p85) and catalytic (p110) subunits [32]. It is activated when p85 binds to IRS 1 through the recognition of its SH2 domain [33]. p110 is then able to catalyse the formation of phosphatidylinositol 3,4,5 triphosphate from Phosphatidylinositol 4,5 biphosphate [25]. PIP3 phosphorylates phosphoinositide dependent protein kinase (PDK 1\&2) which activates Akt/PKB [34], a critical signalling molecule. Akt has over a hundred documented substrates [35] and knockout mice for Akt develop diabetes and insulin resistance [36]. Although, a definitive functional relationship has not been confirmed for all suggested substrates, its extensive cellular network includes phosphorylation of lipid and protein kinases, transcription factors, cell cycle regulators and metabolic enzymes [35]. Glycogen synthase kinase 3 (GSK 3), forkhead box O(Fox 0) family of transcription factors, mammalian target of rapamycin (mTOR) and AS 160 are well known examples. GSK 3 is a serine/threonine protein kinase [37] that inhibits the enzyme glycogen synthase. It has two isoforms GSK3 $\alpha$ and GSK3 $\beta$. Both are inactivated by Akt mediated phosphorylation [35] thereby enhancing glycogen synthase activity and glycogen formation. mTOR is involved in protein synthesis [38] and AS 160 mediates glucose transport across the membrane [39]. FOXO upregulates the transcription of lipogenic and gluconeogenic genes [25]. In the fed state however, akt signalling phosphorylates FOXO and inhibits its transcription by translocating the protein from the nucleus [40].

\section{MAP-kinase pathway}

This pathway is more concerned with cell proliferation, differentiation and growth [41]. It involves Grb2 which is an adapter protein with SH2 domain [41]. As explained earlier, IRS binds to such molecules. Grb2 then binds to Son of Sevenless (Sos), a guanine nucleotide exchange factor which catalyzes the activation of Ras to the active form GTP-Ras. GTP-Ras triggers downstream cascade leading to activation of MAP kinases ERK1\&2 which are involved in genes expression and mitogenesis [25].

\section{Transcriptional Regulation Of Insulin}

Pancreatic duodenal Homeobox 1 (PDX 1) is an essential transcription factor in the regulation of both pancreatic 
development and glucose dependent insulin gene expression. Pancreatic agenesis results from homozygous deletion of PDX1 gene [42] and heterozygous mutation is associated with maturity onset diabetes of the young (MODY) type 4 [43] and other insulin resistant states. PDX 1 binds to critical regions of the insulin promoter e.g. $A_{1}$ and $A_{3}[44]$ to upregulate transcription and also interacts with co-activators e.g. histone acetylase p300 that promote epigenetic modifications. mafA and Beta2/NeuroD1 are transcriptional regulators that bind to $\mathrm{C}_{1}$ and $\mathrm{E}_{1}$ regions of the insulin promoter respectively [44]. Like PDX1 they are stimulated by the presence of glucose. They also interact with PDX1 via network involving other proteins to enhance insulin gene expression.

\section{Glut 4 Translocation}

GLUT 4 is the major glucose transporter in the skeletal muscle and adipose tissue [45]. It transports glucose into the cell upon translocation from the cytosol to the cell membrane. This process is induced by both insulin and physical activity $[45,46]$. Although the pathways are different, they do converge at some point [46]. The insulin mediated pathway is a complex process involving akt substrate (AS) of $160 \mathrm{kDa}$ (TBC1D4), Rab proteins and SNARE proteins. Akt phosphorylation of TBC1D4 inactivates its GTPase activating protein (GAP) activity. The GAP activity is associated with inhibition of Rab GTPase proteins [45]. When activated, Rab GTPase are in the GTP-bound state and are able to regulate vesicular budding, motility, tethering e.t.c[47]. Different members of the Rab GTPase family work in concert with effector molecules to enhance GLUT 4 translocation in the muscles and adipose tissue. In adipocytes, Rab 10 interacts with Sec $16 \mathrm{~A}$ to mobilize GLUT 4 to the membrane [48]. Rab 2A, 8A, 11 and 14 have also been detected in GLUT 4 vesicles in adipocytes [49]. In myocytes, Rab 8A associates with myosin Va for GLUT 4 migration along actin filaments towards the cell surface [50]. Other Rab proteins e.g. 4, 5, 11, 13, 14 e.t.c. also have specified roles in GLUT 4 translocation [45]. The SNARE proteins e.g. VAMP2 (synaptobrevin), syntaxin 4, SNAP 23 along with Munc18C and synip regulate the events e.g. fusion at the membrane. SNARE proteins are classified as vesicle (-v) SNARE located within the vesicle and target $(\mathrm{t})$ SNAREs located in the cell membrane [46]. The interaction between both leads to the formation of a complex (SNARE pin complex) which catalyzes the fusion of vesicles to specific membrane target [51].

\section{Carbohydrate Metabolism}

Insulin acts to clear glucose from the blood and promotes its storage as glycogen. This is achieved by enhancing glycolysis and glycogenesis while inhibiting gluconeogenesis (GNG) and glycogenolysis.

\section{Glycolysis}

glucose is broken down in a series of enzyme catalysed reaction into pyruvate which enters the kreb's cycle [52]. Several enzymes are involved in the glycolytic pathway among which are glucokinase/hexokinase, phosphosphofructokinase, phosphoglycerate kinase and pyruvate kinase [52].
Insulin is an important regulator of hepatic glucokinase [53]. Glucokinase catalyzes the initial rate limiting step in glycolysis i.e. it converts glucose to glucose-6-phosphate thereby acting as a glucose sensor which determines the rate at which glucose metabolism can proceed [54]. Heterozygous mutation of the glucokinase gene is associated with MODY type 2 [53] and homozygous deletion causes permanent neonatal diabetes [55]. Transcriptional upregulation of the enzyme correlates positively with levels of insulin [56]. Hence, glucokinase mRNA activity is increased in the feed state and depressed during prolonged fasting or starvation. This insulin mediated transcription is regulated by sterol regulatory element binding protein 1c (SREBP 1c) [57]. Experiment with cultured rat hepatocytes demonstrated a significant decrease in insulin induced glucokinase expression when SREBP 1c activity was inhibited [57]. Also, inhibitors of PI3-kinase e.g. wortmannin suppressed GCK expression [53]. An indication of the role of Akt dependent signalling. Another enzyme activated by insulin is phosphofructokinase 2 (PFK-2) [58] which catalyzes the formation of fructose 2,6 biphosphate (F-2,6-BP) from fructose-6-phosphate. F-2,6-BP in turn activate phosphofructokinase 1 (PFK-1) which converts F-6-P to F-1,6-BP in a committed step. Also, insulin stimulates pyruvate kinase [59] which converts phosphoenol pyruvate to pyruvate in the final reaction.

\section{Gluconeogenesis}

Insulin regulates hepatic glucose output by exerting a dominant control on GNG. Non carbohydrate substrates are metabolized into glucose during gluconeogenesis and this pathway is essential during fasting, starvation, high intensity exercise e.t.c. Insulin regulates GNG through direct and indirect mechanisms.

\section{Indirect}

Insulin inhibits glucagon production from the $\alpha$-cells [60]. Glucagon promotes GNG by activating PKA [61]. Insulin also inhibits lipolysis and proteolysis thus depriving the liver of GNG substrates [62]. A novel concept of insulin acting on the brain to inhibit hepatic glucose output has equally been advanced [62]. It has been hypothesized that insulin acts on the hypothalamus to alter vagal input to the liver which causes reduced gluconeogenic mRNA expression [63].

\section{Direct}

Transcriptional regulation appears to be the most important manner in which insulin exerts control on GNG. An extensive list of transcription factors has been documented to mediate insulin effect on GNG. In fasting state Fox 01 is activated and it upregulates the transcriptional induction of glucose-6phosphatase (G6Pase) and phosphoenol pyruvate carboxyl kinase (PEPCK) which increases hepatic glucose output. However, akt is able to inactivate Fox01 through phosphorylation causing suppression of GNG [64]. cAMP response binding (CREB) protein is a progluconeogenic transcription factor. cAMP activates PKA with subsequent phosphorylation of CREB at ser. 133 after which it interacts with co-activator CBP/p300 and CRTC2 to mediate transcription of key genes e.g. PEPCK, G6Pase and FBPase [65]. 
Insulin is thought to alter the interaction between CREB and its co-activator $\mathrm{CBP} / \mathrm{p} 300$ thereby reducing GNG [60]. The peroxisome proliferator activated receptor gamma (PPAR $\gamma$ ) coactivator $1 \alpha$ (PGC $1 \alpha$ ) is a transcriptional co-activator which has been shown to interact with several transcription factors e.g. Fox01, SREBP, CBP/p300, HNF $4 \alpha$ e.t.c [66]. It is believed that PGC $1 \alpha$ promotes transcriptional activity of gluconeogenic genes. Akt induced phosphorylation inhibits interaction of PGC $1 \alpha$ with transcription factors [67].

\section{Glycogenesis/Glycogenolysis}

Hormonal regulation of glycogen metabolism occurs through modulating the activity of two important enzymes i.e. glycogen phosphorylase and glycogen synthase. Glycogen synthase synthesizes glycogen from glucose [68] units while glycogen phosphorylase catalyzes the breakdown of glycogen into glucose [69]. Glycogen phosphorylase is activated by protein phosphorylase kinase which itself is phosphorylated by protein kinase A (PKA). Counter regulatory hormones e.g. glucagon and epinephrine activate adenylate cyclase with consequent activation of PKA thereby favouring the persistence of its activation and promoting glycogenolysis [69]. Conversely, insulin inhibits glycogenolysis through activation of protein phosphatase 1 (PP1) [70] and phosphodiesterase enzyme. Activated PP1 deactivates glycogen phosphorylase converting it to the inactive form while phosphodiesterase converts cAMP to AMP thus inactivating PKA. Glycogen synthase enzyme is activated by insulin through inactivation of GSK3 as earlier stated.

\section{Lipid Metabolism}

\section{Lipogenesis}

The increased glucose uptake and glycolysis enhanced by insulin provides substrate for the synthesis of fatty acids (FA) [69]. Pyruvate dehydrogenase (PD) converts pyruvate to acetyl CoA [71] which is the starting material for FA synthesis. Insulin activates pyruvate dehydrogenase phosphatase which dephosphorylates PD [72]. It also activates acetyl CoA carboxylase which converts acetyl CoA into malonyl CoA [73] in the committed step of FA synthesis. By promoting the induction of genes coding for the enzyme, the expression of fatty acid synthase (a complex of enzymes that catalyse multiple steps in FA biosynthesis) is increased by the activation of the sterol-regulatory-elementbinding-protein 1c (SREBP 1c) $[74,75]$. In addition, the activity of lipoprotein lipase which hydrolyzes triglycerides in the chylomicrons and VLDL into free FA (FFA) and monoacylglycerol that are taken up by tissues for storage is stimulated by insulin [76].

\section{Lipolysis}

It is the process of hydrolysing triglycerides into FA and glycerol which requires the enzyme hormone sensitive lipase (DAGL) which is inhibited by insulin [77]. Other enzymes involved in lipolysis are adipose triglyceride lipase (ATGL) and the recently discovered monoacylglycerol lipase (MAGL). Lipolysis is promoted by glucagon and catecholamines through PKA dependent phosphorylation [78] which is opposed by akt

\section{Protein}

Insulin stimulates the cellular uptake of AA that are required for protein synthesis. In the skeletal muscles it facilitates the uptake of branched chain AA and prevents protein catabolism [79]. Hepatic albumin synthesis could be reduced in patients with diabetes because of the role insulin plays in the expression of albumin gene. Insulin receptor knockout mice exhibited reduced serum albumin levels and Akt 1,2 knockout resulted in severe hypoalbuminemia [80] which underscores the necessity for insulin signalling pathway. mTOR, a serine/threonine kinase which exist in two complexes i.e. mTORC1 and mTORC2 plays an indispensable role in protein synthesis. Knockout mice for mTOR die in-utero [81]. It regulates the translation of mRNA into proteins through substrate phosphorylation e.g. eukaryotic initiation factor 4E (eIF-4E) binding protein 1 (4E$\mathrm{BP} 1)$ and p70 ribosomal protein S6 kinase (S6KI) [82]. 4E-BP1 inhibits translation initiation by binding eIF4E which enhances ribosomes mobilization to the 5! end of mRNA. S6K1 is involved in translation regulation through the phosphorylation of PDCD4 (a negative regulator of eIF4A) and inactivation of eukaryotic elongation factor 2 (EEF 2) kinase which inhibits EEF 2 thus promoting the elongation phase of translation [83].

\section{Vasculature}

The role of insulin in the maintenance of vascular integrity is well documented. Insulin resistant or deficiency states are characterized by endothelial dysfunction induced vasculopathy [84]. The synthesis of nitric oxide (NO) by the endothelial cells is enhanced by insulin and NO is involved in a vast array of biologic functions like regulation of blood flow, systemic inflammation, angiogenesis and smooth muscle proliferation. It is also involved in synaptic transmission, inhibition of platelets aggregation, maintenance of endothelial structural integrity and regulation of apoptosis [84].

Insulin stimulates endothelin-1 production by the endothelial cells $[85,86]$. It has equally been linked to sympathetic nervous system activation [87] and renal sodium retention [88]; actions that have been suggested to increase blood pressure in insulin resistant state. Endothelin is a potent vasoconstrictor and its production is enhanced by the MAPK pathway [89]. Insulin acts on specific targets in the nephron to increase tubular reabsorption of $\mathrm{Na}+$ as observed from multiple studies. In the proximal tubules it increases the activity of $\mathrm{Na}^{+} \mathrm{H}^{+}$exchanger type III (NHE III) and $\mathrm{Na}^{+} / \mathrm{K}^{+}$-ATPase [90]. $70 \%$ of $\mathrm{Na}^{+}$reabsorption occurs in the PCT. In the loop of Henle, it acts on both $\mathrm{Na}^{+}-\mathrm{K}^{+}$-ATPase and $\mathrm{Na}^{+}-\mathrm{K}^{+}-$ $2 \mathrm{Cl}$ transporter [91]. In rats, C-peptide was reported to stimulate Loop of Henle $\mathrm{Na}^{+} / \mathrm{K}^{+}$-ATPase activity [92]. Current evidence suggests that insulin stimulates SNS particularly in obese and insulin resistant individuals. A possible explanation is that this occurs as an attempt by the body to increase metabolic rate and restore energy balance [87]. Unfortunately, this inadvertently contribute to increased blood pressure. 


\section{Cell Growth}

Insulin is involved in foetal and post-natal growth partly as a result of its anabolic effects. Foetal insulin deficiency is associated with intrauterine growth restriction and increased risk of developing T2DM later in life [93]. Hence, insulin deficiency is associated with reduced growth in children. The cell growth effects of insulin are mediated by binding to both IR and insulin like growth factor (IGF) receptor [94]. IGF-1 shares structural similarity with insulin and its receptor also possess tyrosine kinase activity $[94,95]$.

Insulin enhances and modulates the activity of several growth factors e.g. platelet derived growth factor (PDGF), epidermal growth factor (EGF), vascular endothelial growth factor (VEGF) and others $[94,96]$. It is capable of stimulating the Ras-Raf-MAPK pathway which is involved in a multitude of mitogenic processes including cell division, differentiation, proliferation and growth [97].

Insulin enhances wound healing partly through its stimulatory effect on protein anabolism. It has been shown to exert a modulating influence on matrix metalloproteinase at wound site [98]. During angiogenesis it undertakes multiple actions including pericyte mobilization and proliferation, proliferation of smooth muscles, fibroblasts and epithelial cells [99]. Indeed, local injection of insulin into diabetic foot ulcer improved the growth of granulation tissue and topical insulin accelerated wound healing in chronic ulcers $[100,101]$.

\section{Chronic Inflammation}

Transcriptional factor NF-kb promotes the expression of pro-inflammatory genes for several molecules e.g. cytokines, chemokines and adhesion molecules [102]. IL-1, IL- 6 and TNF- $\alpha$ are involved in chronic inflammatory conditions e.g. obesity, DM and atherosclerosis [102], and the production of these cytokines is induced by NF-kb. Studies in obese subjects have revealed that insulin significantly reduced the expression of this transcription factor and this result has been replicated in studies using human aortic endothelial cells [103]. Specifically, the expression of TNF- $\alpha$, which is capable of stimulating the production of other cytokines is suppressed by insulin. Also, the Akt-eNOs-NO pathway is involved in the inhibition of intracellular adhesion molecule 1 (ICAM 1), monocyte chemoattractant protein 1 (MCP 1) and p-selectin [104]. Morever, insulin supresses Toll-likereceptors (TLRs) which have been documented to be involved in myocardial inflammation and damage, inhibits plasminogen activator inhibitor 1 (PAI 1), reduces reactive oxygen species (ROS) generation and C-reactive protein (CRP) levels [104, 105].

\section{Other Effects}

Insulin promotes the influx of potassium into the cells by increasing the activity of $\mathrm{Na}^{+} / \mathrm{k}^{+}$-ATPase pump which found in essentially every cell and exchanges $\mathrm{Na}+$ for $\mathrm{K}+$ [106]. This underlies its use in the treatment of acute hyperkalaemia. It was previously suggested that exogenous insulin is associated with increased gastric acid secretion but this has been shown to occur mostly in hypoglycaemia induced vagal stimulation [107].
Insulin is involved in the central regulation of appetite and energy expenditure by reducing the expression of neuropeptide $\mathrm{Y}$ and stimulating pro opiomelanocortin [108]. It has recently been reported that insulin could improve memory and intelligence [109].

\section{Conclusion}

The study of the physiological actions of insulin and its signal transduction pathway has led to important discoveries in the management of diabetes. Despite the success achieved so far multiple potential targets still await exploration through molecular and translational research. GLUT 4 appears to be the quintessential insulin sensitivity molecule based on the crucial job it does of transporting glucose into myocytes and adipocytes. Furthermore, its expression is upregulated by both insulin and physical exercise which speaks volume of its indispensable role in insulin actions. Research focused around this molecule may hold some promise in the treatment of prediabetes and diabetes. 


\section{References}

1. Zhuo Fu, Elizabeth R. Gilbert, Dongmin Liu. Regulation of Insulin Synthesis and Secretion and Pancreatic Beta-Cell Dysfunction in Diabetes. Current Diabetes Review.2013; 9(1): 25-53.

2. Pittman I, Philipson L, Steiner D. Insulin biosynthesis, secretion, structure, and structure-activity relationships. 2004

3. Brange $J$ and Langkjoer L. Insulin structure and stability. Pharm Biotechnol. 1993; 5: 315-350.

4. Michael A. Weiss. The Structure and Function of Insulin: Decoding the TR Transition. Vitamins and Hormones 2009; 80: 33-49.

5. Adams MJ, Blundell TL, Dodson EJ, Dodson GG, Vijayan M, Baker EN, et al. Structure of rhombohedral 2 zinc insulin crystals. Nature. 1969; 224:491-495.

6. Schlichtkrull J. Insulin Crystals: Chemical and Biological Studies on Insulin Crystals and Insulin Zinc Suspensions. Kobenhavns universitet; Copenhagen, Munksgaard.1958;139.

7. Derewenda U, Derewenda Z, Dodson EJ, Dodson GG, Reynolds CD, Smith GD, et al. Phenol stabilizes more helix in a new symmetrical zinc insulin hexamer. Nature. 1989; 338:594-596.

8. Gisela Wilcox. Insulin and Insulin Resistance. Clinical Biochemist Review.2005; 26(2): 19-39.

9. Wu L, Fritz JD, Powers AC. Different functional domains of GLUT2 glucose transporter are required for glucose affinity and substrate specificity. Endocrinology. 1998;139(10):4205-4212.doi: 10.1210/ endo.139.10.6245

10. Soria B, Quesada I, Ropero AB, Pertusa JA, Martín F, Nadal A. Novel players in pancreatic islet signaling: from membrane receptors to nuclear channels. Diabetes. 2004; 53 (Suppl 1):S86-S91.

11. Peter Proks, Frank Reimann, Nick Green, Fiona Gribble, Frances Ashcroft. Sulfonylurea Stimulation of Insulin Secretion. Diabetes.2002; 51(suppl 3): S368-S376.

12. Tucker SJ, Gribble FM, Zhao C, Trapp S, Ashcroft FM, Truncation of Kir6.2 produces ATP-sensitive K-channels in the absence of the sulfonylurea receptor. Nature387.1997;179-181.

13. Gribble FM, Tucker SJ, Seino S, Ashcroft FM. Tissue specificity of sulphonylureas: studies on cloned cardiac and beta-cell KATP channels. Diabetes.1998;47(9):1412 -1418.

14. Proks P and Ashcroft FM. Phentolamine block of K-ATP channels is mediated by Kir6.2. Proc Natl Acad Sci U S A. 1997;94(21) :117 16 -11720 .

15. Gribble FM, Davis TME, Higham CE, Clark A, Ashcroft FM. The antimalarial agent mefloquine inhibits ATP-sensitive K-channels. Br J Pharmacol.2000;131(4):756 -760.doi:10.1038/sj.bjp.0703638

16. Troitza K, Bratanova-Tochkova, Haiying Cheng, Samira Daniel, Subhadra Gunawardana, Yi-Jia, et al. Triggering and Augmentation Mechanisms, Granule Pools, and Biphasic Insulin Secretion. Diabetes. 2002; 51(2): S83-S90.

17. Ashcroft FM and Rorsman P. Electrophysiology of the pancreatic betacell. Prog Biophys Mol Biol.1989;54(2):87-143. doi:10.1016/00796107(89)90013-8

18. William A. Catterall. Voltage-Gated Calcium Channels. Cold Spring Harb Perspect Biol. 2011; 3(8): a003947. doi: 10. 1101/c sh perspect. a003947
19. Shao-Nian Yang and Per-Olof Berggren. $\beta$-Cell CaV channel regulation in physiology and pathophysiology. American Journal of Physiology Endocrinology and Metabolism.2005;288(1): E16 -E28. doi:10.1152/ ajpendo.00042.2004

20.Sharp GWG. The adenylate cyclase-cyclic AMP system in islets of Langerhans and its role in the control of insulin release. Diabetologia. 1979;16(5):287-296.

21. Patrick E. MacDonald, Wasim El-kholy, Michael J. Riedel, Anne Marie F. Salapatek, Peter E. Light Michael B. Wheeler. The Multiple Actions of GLP-1 on the Process of Glucose-Stimulated Insulin Secretion. Diabetes.2002; 51(suppl 3): S434-S442. doi:10.2 337/

diabetes.51.2007.S434

22. Beguin P, Nagashima K, Nishimura M, Gonoi T, Seino S. PKAmediated phosphorylation of the human KATP channel: separate roles of Kir6.2 and SUR1 subunit phosphorylation. The EMBO Journal.1999;18(17):4722 -4732.

23. Del Prato $S$ and Tiengo A. The importance of first-phase insulin secretion: implications for the therapy of type 2 diabetes mellitus. Diabetes/Metabolism Research and Review. 2001;17(3):164-174. doi:10.1002/dmrr.198

24. John E. Gerich. Is Reduced First-Phase Insulin Release the Earliest Detectable Abnormality in Individuals Destined to Develop Type 2 Diabetes? Diabetes.2002; 51(suppl 1): S117-S121.doi:10.2337/ diabetes.51.2007.S117

25. Jérémie Boucher, André Kleinridders, C. Ronald Kahn. Insulin Receptor Signalling in Normal and Insulin-Resistant States. Cold Spring Harbour Perspective in Biology.2014;6(1): a009191. doi: 10.1101/cshperspect. a009191

26. Ullrich A, Bell JR, Chen EY, Herrera R, Petruzelli LM, Dull TJ, et al. Human insulin receptor and its relationship to the tyrosine kinase family of oncogenes. Nature.1985;313:765-761.

27. Sun XJ, Rothenberg P, Kahn CR, Backer JM, Araki E, Wilden PA, et al. Structure of the insulin receptor substrate IRS-1 defines a unique signal transduction protein. Nature. 1991;352:73-77.

28. Voliovitch H, Schindler DG, Hadari YR, Taylor SI, Accili D, Zick Y. Tyrosine phosphorylation of insulin receptor substrate-1 in vivo depends upon the presence of its pleckstrin homology region. Journal of Biological Chemistry.1995; 270(30):18083-18087. doi: 10.1074/ jbc.270.30.18083

29. Sun XJ, Crimmins DL, Myers MG Jr, Miralpeix M, White MF. Pleiotropic insulin signals are engaged by multisite phosphorylation of IRS1. Molecular and Cellular Biology. 1993; 13(12):7418-7428. doi: 10.1128/MCB.13.12.7418

30. Taniguchi CM, Emanuelli B, Kahn CR. Critical nodes in signalling pathways: insights into insulin action. Nature Reviews Molecular Cell Biology. 2006; 7: 85-96.

31. De Meyts P, Feingold KR, Anawalt B, Boyce A, Chrousos G, Dungan K, et al. The Insulin Receptor and Its Signal Transduction Network. Endotext.

32. Vadas O, Burke JE, Zhang X, Berndt A, Williams RL. Structural basis for activation and inhibition of class I phosphoinositide 3-kinases. Science Signaling. 2011;4(195):re2. doi: 10.1126/scisignal.2002165

33. M G Myers, Jr, J M Backer, X J Sun, S Shoelson, P Hu, J Schlessinger, et al. IRS-1 activates phosphatidylinositol 3'-kinase by associating 
with src homology 2 domains of p85. Proceedings of the National Academy of Science U S A. 1992; 89(21): 10350-10354. doi:10.1073/ pnas.89.21.10350

34. Alessi DR, James SR, Downes CP, Holmes AB, Gaffney PR, Reese CB, et al. Characterization of a 3-phosphoinositide-dependent protein kinase, which phosphorylates and activates protein kinase $\mathrm{B} \alpha$. Curr Biol.1997;7(4): 261-269.doi:10.1016/S0960-9822(06)00122-9

35. Brendan D. Manning and Alex Toker. AKT/PKB Signaling: Navigating the Network. Cell. 2017;169(3): 381-405.doi:10.1016/

j.ce ll.2017.04.001

36. Cho H, Mu J, Kim JK, Thorvaldsen JL, Chu Q Crenshaw EB III, et al. Insulin resistance and a diabetes mellitus-like syndrome in mice lacking the protein kinase Akt2 (PKB $\beta$ ). Science.2001;292(5522): 1728-1731. doi: 10.1126/science.292.5522.1728

37. Cross DA, Alessi DR, Cohen P, Andjelkovich M, Hemmings BA. Inhibition of glycogen synthase kinase-3 by insulin mediated by protein kinase B. Nature. 1995; 378:785-789.

38. Claudio De Virgilioa and Robbie Loewith. The TOR signalling network from yeast to man. The International Journal of Biochemistry \& Cell Biology. 2006;38(9):1476-1481.doi: 10.1016/j.biocel.2006.02.013

39. Ferenc Szekeres, Alexandra Chadt, Robby Z. Tom, Atul S Deshmukh, AlexanderVChibalin, Marie Bjornholm, etal.The Rab-GTPaseActivating Protein TBC1D1 Regulates Skeletal Muscle Glucose Metabolism. American Journal of physiology, endocrinology and metabolism. 2012;303(4):E524-E533.doi:10.1152/ajpendo.00605.2011

40. Brunet A, Bonni A, Zigmond MJ, Lin MZ, Juo P, Hu LS, et al. Akt promotes cell survival by phosphorylating and inhibiting a Forkhead transcription factor. Cell. 1999;96(6):857-868. doi:10.1016/S00928674(00)80595-4

41. Skolnik EY, Batzer A, Li N, Lee CH, Lowenstein E, Mohammadi M ,et al. The function of GRB2 in linking the insulin receptor to Ras signaling pathways. Science.1993; 260(5116): 1953-1955. doi: 10.1126/ science. 8316835

42. Jonsson J, Carlsson L, Edlund T, Edlund H. Insulin-promoter factor 1 is required for pancreatic development in mice. Nature.1994; 371:606609.

43. Stoffers DA, Stanojevic V, Habener JF. Insulin promoter factor-1 gene mutation linked to early-onset type 2 diabetes mellitus directs expression of a dominant negative isoprotein. J Clin Invest.1998;102(1):232 -241.

44.Vincent Poitout, Derek Hagman, Roland Stein, Isabella Artner, R. Paul Robertson, Jamie S. Harmon. Regulation of the Insulin Gene by Glucose and Fatty Acids. J Nutr. 2006; 136(4): 873-876. doi: 10.1093/ jn/136.4.873

45. Tokarz VL, MacDonald PE, Klip A. The cell biology of systemic insulin function. J Cell Biol. 2018;217(7):2273-2289.doi: 10. 10 83/ jcb.201802095.

46. Richter EA and Hargreaves M. Exercise, GLUT4, and Skeletal Muscle Glucose Uptake. Physiol Rev. 2013;93(3):993-1017. doi: 10.11 52/ physrev.00038.2012.

47. Kaddai V , Le Marchand-Brustel Y, Cormont M. Rab proteins in endocytosis and Glut4 trafficking. Acta Physiol (Oxf). 2008; 192(1): 75-88. doi: 10.1111/j.1748-1716.2007.01787.x.

48. Sano H, Roach W.G, Peck G.R, Fukuda M, Lienhard G.E. Rab10 in insulin-stimulated GLUT4 translocation. Biochem J.2008; 411 (1): 8995.doi:10.1042/BJ20071318.

49. Larance M, Ramm G, Stockli J, van Dam EM, Winata S, Wasinger $\mathrm{V}$, et al. Characterization of the role of the Rab GTPase-activating protein AS160 in insulin-regulated GLUT4 trafficking. J Biol Chem.2005;280(45):37803-37813.

50.Sun Y, Chiu TT, Foley KP, Bilan PJ, Klip A. Myosin Va mediates Rab8Aregulated GLUT4 vesicle exocytosis in insulin-stimulated muscle cells. Mol. Biol. Cell. 2014;25(7):1159-1170. doi: 10.1091/mbc.E13-080493.

51. Hong W. Protein transport from the endoplasmic reticulum to the Golgi apparatus. J Cell Sci.1998;111(Pt 19): 2831-2839.

52. Li XB, Gu JD, Zhou QH. Review of aerobic glycolysis and its key enzymes - new targets for lung cancer therapy.Thorac Cancer.2015 ; 6(1):1724. doi: 10.1111/1759-7714.12148.

53. P. B. Iynedjian. Molecular Physiology of Mammalian Glucokinase. Cellular and Molecular Life Sciences. 2009; 66(1): 27-42.

54. Magnuson M. A and Matschinsky F. M. Glucokinase as a glucose sensor: past, present and future. Glucokinase and Glycemic: Disease: From Basics to Novel Therapeutics. Front Diabetes.2004;16:1-17. doi:10.1159/000079003

55. Njolstad P.R, Sagen J.V, Bjorkhaug L, Odili S, Shehadeh N, Bakry D, et al. Permanent neonatal diabetes caused by glucokinase deficiency: inborn error of the glucose-insulin signaling pathway. Diabetes. 2003; 52(11): 2854-2860. doi: 10. 2337/diabetes.52. 11.2854

56. Iynedjian P. B, Gjinovci A, Renold A. E. Stimulation by insulin of glucokinase gene transcription in liver of diabetic rats. journal of biological Chemistry.1988; 263:740-744.

57. Foretz M, Guichard C, Ferré P, Foufelle F. Sterol regulatory element binding protein- $1 \mathrm{c}$ is a major mediator of insulin action on the hepatic expression of glucokinase and lipogenesis-related genes. Proc Natl Acad Sci U S A. 1999;96(22):12737-12742.

58. MullerA,Unthan-Fechner K, Probst I. Activation of phosphofructokinase 2 by insulin in cultured hepatocytes without accompany changes of effector levels or cAMP-stimulated protein kinase activity ratios. Eur J Biochem. 1988;176(2):415-420.

59. WC Parks and RL drake. Insulin mediates the stimulation of pyruvate kinase by a dual mechanism. Biochem J. 1982; 208(2):333-337. doi: $10.1042 /$ bj2080333.

60. Maximilian Hatting, Clint D. J. Tavares, Kfir Sharabi, Amy K. Rines, Pere Puigserver. Insulin regulation of gluconeogenesis. Ann N Y Acad Sci. 2018; 1411(1): 21-35. doi: 10.1111/nyas.13435.

61. Altarejos JY and Montminy M. CREB and the CRTC co-activators: sensors for hormonal and metabolic signals. Nat Rev Mol Cell Biol. 2011;12(3):141-151. doi: 10.1038/nrm3072.

62. Jean Girard. Insulin's effect on the liver: "Direct or indirect?" continues to be the question. J Clin Invest. 2006;116(2):302-304.doi: 10.1172/ JCI27743.

63. Alan D Cherrington, Dale S Edgerton, Christopher J Ramnanan. THE ROLE OF INSULIN IN THE REGULATION OF PEPCK AND GLUCONEOGENESIS IN VIVO. US Endocrinology, 2009;5(1):34-39. doi:10.17925/USE.2009.05.1.34.

64. Tzivion G, Dobson M, Ramakrishnan G. FoxO transcription factors; Regulation by AKT and 14-3-3 proteins. Biochim Biophys Acta. 2011; 
1813(11):1938-1945. doi: 10.1016/j.bbamcr.2011.06.002.

65. Herzig S, Long F, Jhala US, Hedrick S, Quinn R, Bauer A, et al. CREB regulates hepatic gluconeogenesis via the co-activator PGC-1. Nature. 2001; 413(6852):179-183.

66. Lin J, Handschin C, Spiegelman BM. Metabolic control through the PGC-1 family of transcription coactivators. Cell Metab. 2005;1(6): 361 -370 .

67. Puigserver P, Rhee J, Donovan J, Walkey CJ, Yoon JC, Oriente F, et al. Insulin-regulated hepatic gluconeogenesis through FOXO1-PGC1alpha interaction. Nature. 2003;423(6939):550-555.

68. Agius L. Glucokinase and molecular aspects of liver glycogen metabolism. Biochem J. 2008;414(1):1-18. doi: 10.1042/BJ20080595.

69. Liangyou Rui. Energy Metabolism in the Liver. Compr Physiol.2014;4(1):177-197. doi: 10.1002/cphy.c130024.

70. Zhang T, Wang S, Lin Y, Xu W, Ye D, Xiong Y, et al. Acetylation negatively regulates glycogen phosphorylase by recruiting protein phosphatase 1. Cell Metab. 2012;15(1):75-87. doi: 10.1016/j.cmet.2011.12.005.

71. Patel MS, Nemeria NS, Furey W, Jordan F. The Pyruvate Dehydrogenase Complexes: Structure-based Function and Regulation. J Biol Chem.2014;289(24):16615-16623. doi: 10.1074/jbc.R114.563148.

72. Feldhoff PW, Arnold J, Oesterling B, Vary TC. Insulin-induced activation of pyruvate dehydrogenase complex in skeletal muscle of diabetic rats. Metabolism.1993; 42 (5): 615-623.

73. L A Witters, T D Watts, D L Daniels, J L Evans. Insulin stimulates the dephosphorylation and activation of acetyl-CoA carboxylase. Proc Natl Acad Sci U S A. 1988; 85(15): 5473-5477. doi: 10.1073/ pnas.85.15.5473.

74. Horton JD, Goldstein JL, Brown MS. SREBPs: activators of the complete program of cholesterol and fatty acid synthesis in the liver. J Clin Invest. 2002; 109(9): 1125-1131. doi: 10.1172/JCI15593.

75. Wan M, Leavens KF, Saleh D, Easton RM, Guertin DA, Peterson TR, et al. Postprandial hepatic lipid metabolism requires signaling through Akt2 independent of the transcription factors FoxA2, Fox01, and SREBP1c. Cell Metab. 2011;14(4):516-527. doi:10.1016/j.cm e t.2011.09.001.

76. Kraemer FB, Takeda D, Natu V, Sztalryd C. Insulin regulates lipoprotein lipase activity in rat adipose cells via wortmannin- and rapamycinsensitive pathways. Metabolism. 1998;47(5):555-559.

77. Belfrage P, Fredrikson G, Olsson H, Stralfors P. Molecular mechanisms for hormonal control of adipose tissue lipolysis. Int J Obes.1985;9 Suppl 1:129-135.

78. Samra JS, Clark ML, Humphreys SM, MacDonald IA, Bannister PA, Frayn KN. Effects of physiological hypercortisolemia on the regulation of lipolysis in subcutaneous adipose tissue. J Clin Endocrinol Metab.1998;83(2):626-631.

79. Brooks DC, Bessey PQ Black PR, Aoki TT, Wilmore DW. Insulin stimulates branched chain amino acid uptake and diminishes nitrogen flux from skeletal muscle of injured patients. J Surg Res. 1986;40(4):395-405.

80. Chen Q Lu M, Monks BR, Birnbaum MJ. Insulin Is Required to Maintain Albumin Expression by Inhibiting Forkhead Box 01 Protein. J Biol Chem. 2016;291(5):2371-2378. doi: 10.1074/jbc.M115.677351.

81. Gangloff YG, Mueller M, Dann SG, Svoboda P, Sticker M, Spetz JF, et al. Disruption of the mouse mTOR gene leads to early postimplantation lethality and prohibits embryonic stem cell development. Mol Cell
Biol. 2004;24(21):9508-9516.

82. Wang X and Proud CG. The mTOR Pathway in the Control of Protein Synthesis. Physiology (Bethesda). 2006;21:362-369.

83. Dorrello NV, Peschiaroli A, Guardavaccaro D, Colburn NH, Sherman NE, Pagano M. S6K1- and betaTRCP-mediated degradation of PDCD4 promotes protein translation and cell growth. Science. 2006;314(5798):467-471.

84. Ranganath Muniyappa, Micaela Iantorno, Michael J Quon. An Integrated View of Insulin Resistance and Endothelial Dysfunction. Endocrinol Metab Clin North Am. 2008; 37(3): 685-x. doi: 10.1016/j. ecl.2008.06.001.

85. Cardillo C, Nambi SS, Kilcoyne CM, Choucair WK, Katz A, Quon MJ, et al. Insulin stimulates both endothelin and nitric oxide activity in the human forearm. Circulation. 1999;100(8):820-825.

86. Pantelis A. Sarafidis and George L. Bakris. Insulin and Endothelin: An Interplay Contributing to Hypertension Development? The Journal of Clinical Endocrinology \& Metabolism.2007;92(2): 379-385. doi:10.1210/jc.2006-1819.

87. Landsberg L. Insulin and the sympathetic nervous system in the pathophysiology of hypertension. Blood Press Suppl. 1996;1:25-29.

88. Michael W. Brands and M. Marlina Manhiani. Sodium-retaining effect of insulin in diabetes. Am J Physiol Regul Integr Comp Physiol. 2012; 303(11): R1101-R1109. doi: 10.1152/ajpregu.00390.2012.

89. Potenza MA, Marasciulo FL, Chieppa DM, Brigiani GS, Formoso G, Quon MJ, et al. Insulin resistance in spontaneously hypertensive rats is associated with endothelial dysfunction characterized by imbalance between NO and ET-1 production. Am J Physiol Heart Circ Physiol. 2005;289(2):H813-H822.

90. Gesek FA and Schoolwerth AC. Insulin increases $\mathrm{Na}+\mathrm{-H}+$ exchange activity in proximal tubules from normotensive and hypertensive rats. Am J Physiol. 1991;260(5 Pt 2):F695-F703.

91. Nobuyuki Takahashi and Keishi Abe. Tubular effects of insulin. Hypertension Research. 1996;19(1): S41-S45. doi: 10.1291/ hypres.19. SupplementI_S41.

92. Shoko Horita, George Seki, Hideomi Yamada, Masashi Suzuki, Kazuhiko Koike, Toshiro Fujita. Insulin Resistance, Obesity, Hypertension, and Renal Sodium Transport. Int J Hypertens. 2011; 2011: 391762. doi: 10.4061/2011/391762.

93. Terauchi Y, Kubota N, Tamemoto H, Sakura H, Nagai R, Akanuma Y, et al. Insulin effect during embryogenesis determines fetal growth: a possible molecular link between birth weight and susceptibility to type 2 diabetes. Diabetes. 2000; 49(1): 82-86.

94. Straus DS. Growth-stimulatory actions of insulin in vitro and in vivo. Endocr Rev. 1984;5(2):356-369.

95. Dupont J, Khan J, Qu BH, Metzler P, Helman L, LeRoith D. Insulin and IGF-1 Induce Different Patterns of Gene Expression in Mouse Fibroblast NIH-3T3 Cells: Identification by cDNA Microarray Analysis. Endocrinology.2001;142(11):4969-4975.

96. Goalstone ML, Leitner JW, Wall K, Dolgonos L, Rother KI, Accili D, et al. Effect of insulin on farnesyltransferase. Specificity of insulin action and potentiation of nuclear effects of insulin-like growth factor-1, epidermal growth factor, and platelet-derived growth factor.J Biol Chem. 1998;273(37):23892-23896.

97. Draznin B. Mitogenic action of insulin: friend, foe or 'frenemy'? 
Diabetologia. 2010;53(2):229-233. doi: 10.1007/s00125-009-15586.

98. Guo J, Dhaliwall J.K, Chan K.K, Ghanim H, Al Koudsi N, Lam L, et al. In vivo Effect of Insulin to Decrease Matrix Metalloproteinase-2 and -9 Activity after Arterial Injury. J Vasc Res 2013;50(4):279-288. doi:10.1159/000351611.

99. Carlos A. Escudero, Kurt Herlitz, Felipe Troncoso, Katherine Guevara, Jesenia Acurio, Claudio Aguayo, et al. Pro-angiogenic Role of Insulin: From Physiology to Pathology. Front. Physiol.2017;8:204. doi: 10.3389/fphys.2017.00204

100. Zhaoxin Zhang and Lei Lv. Effect of local insulin injection on wound vascularization in patients with diabetic foot ulcer. Exp Ther Med. 2016; 11(2): 397-402.doi: 10.3892/etm.2015.2917.

101. Gaurav Goenka, Virendra S Athavale, Dakshayani S Nirhale, Nitin Deshpande, Kunal Agrawal, Murtuza Calcuttawala. Role of topical use of insulin in healing of chronic ulcer. Med J DY Patil Univ 2014;7(5):579-583. doi: 10.4103/0975-2870.140400.

102. Ting Liu, Lingyun Zhang, Donghyun Joo, Shao-Cong Sun. NF-кB signaling in inflammation. Signal Transduction and Targeted Therapy. 2017; 2: e17023. doi:10.1038/sigtrans.2017.23.

103. Paresh Dandona, Ahmad Aljada, Priya Mohanty, Husam Ghanim, Wael Hamouda, Ezzat Assian, et al. Insulin Inhibits Intranuclear Nuclear Factor $\kappa$ B and Stimulates IкB in Mononuclear Cells in Obese
Subjects: Evidence for an Anti-inflammatory Effect? The Journal of Clinical Endocrinology \& Metabolism.2001;86(7): 3257-3265. doi:10.1210/jcem.86.7.7623.

104. Sun Q, LiJ, Gao F. New insightsinto insulin:Theanti-inflammatory effect and its clinical relevance. World J Diabetes.2014;5(2):89-96. doi: 10.4239/wjd.v5.i2.89.

105. Chaudhuri A, Janicke D, Wilson MF, Tripathy D, Garg R, Bandyopadhyay A, et al. Anti-inflammatory and profibrinolytic effect of insulin in acute ST-segment-elevation myocardial infarction. Circulation. 2004;109(7):849-854.

106. Mushiyakh Y, Dangaria H, Qavi S, Ali N, Pannone J, Tompkins D. Treatment and pathogenesis of acute hyperkalemia. J Community Hosp Intern Med Perspect. 2012;1(4). doi: 10.3402/jchimp.v1i4.7372. 107. Michael A. Polacek and Edwin H. Ellison. Insulin-Induced Stimulation of Gastric Acid Secretion. JAMA. 1963;183(12):10061007. doi:10.1001/jama.1963.63700120009009c.

108. Michael W. Schwartz, Stephen C. Woods, Daniel Porte Jr, Randy J. Seeley, Denis G. Baskin. Central nervous system control of food intake. Nature.2000;404:661-671.

109. Lee WL and Klip A. Endothelial Transcytosis of Insulin: Does It Contribute to Insulin Resistance? Physiology (Bethesda).2016;31(5):336 -345. doi: 10.1152/physiol.00010.2016. 